\title{
Is Strategic and Sustainable Leadership Synonymous With Effective Leadership?
}

\author{
Anna Saiti \\ University of West Attica
}

\begin{abstract}
The purpose of this study is, after a thorough analysis of the relevant literature, to investigate whether strategic/sustainable leadership and effective leadership - key concepts for the educational sector - are synonymous or whether they complement each other, and indeed whether there is an interdependence between these concepts of leadership. The effectiveness of the school (and any organization) depends on the efficient use of available resources and on the implementation of strategic/sustainable leadership. The coexistence of all members in the school's leadership and the creation of collaborative social networks are the basic elements for establishing school sustainability.
\end{abstract}

Keywords: effective leadership, strategic leadership, leader, sustainable leadership

\section{INTRODUCTION}

The issue of effective leadership is extremely critical and is a popular topic of discussion in studies in the field of leadership. That is to say, a leader must adopt an appropriate leadership style and behavior in order to be effective. Leadership in any sector of the economy, and therefore in education, needs to be effective in influencing behavior and in adapting the leadership role to new working environments with different circumstances, tasks and individuals (including educators). School effectiveness calls for problems to be identified and solutions found.

In recent years, there has been increasing discussion of sustainable leadership, which is more than a matter of social responsibility and an organization's (school's) environment. Leadership research indicates that a leader needs to engage in sustainable leadership practices in order to achieve the desired results more swiftly, which is basically a continuous process of improving the educational services as well as the dynamics of the school unit (Conway, 2015; Day \& Sammons, 2013; Day, Gu \& Sammons, 2016; Harris, 2005, 2008 2010; Harris \& Spillane, 2008; Spillane, 2006; Tian, Riskou \& Collin, 2015). Sustainable leadership is deeply rooted in the communication between the staff members and the leader. A school leader should communicate efficiently any information or knowledge that could help improve school performance so that school staff members develop the right mentality for achieving the school's goals and the school's head controls the working environment. Sustainable leadership encompasses efficiency, for which the available resources (both human and material) need to be harnessed and used effectively in order to respond directly to challenges and needs.

Successful leadership is based on the ability of an individual (the school head/leader) to manage in a way that serves the goals of the school unit. This ability is a matter of power: leadership is essentially about how the manager uses the power granted to them by their position to influence the behavior of the staff 
members (Day \& Sammons, 2013). Hence, there is a dependency in the relationship between the school head/leader and the staff members.

Changing the behavior of school unit members is very much dependent on cultivating a positive climate, positive emotions and a sense of well-being in the workplace (the school environment). Relevant studies (Bush, 2008; Day, Gu \& Sammons, 2016; Harris, 2008, 2010; Harris \& Spillane, 2008; Ireland \& Hitt, 1999; Iszatt-Whire \& Saunders, 2020; Liedtka, 2000; Robertson, 2011; Sergiovanni, 1992, 1994; Spillane, 2006) have revealed that cultivating positive emotions leads to success and to improvements in work performance. Indeed, every leader's strategy should be people-centered to create a healthy basis for improving the school unit

It is clear that the abilities of a school leader (or any leader) and their personality traits are crucially significant. Some people think that they can become effective school leaders simply by acquiring the necessary skills. Others believe that they can become great leaders simply by developing their character. Both are wrong. A leader needs both skills and personality (Day, Gu \& Sammons, 2016).

The skills as well as the personality traits of a school leader influence their leadership behavior, which is a complex and multidimensional process (Conway, 2015; Fullan, 2005; Hargreaves \& Fink, 2008; Judge, Bono, Ilies \& Gerhardt, 2002; Kempster, Iszatt-White \& Brown, 2019). It is a phenomenon that has a strong correlation with choices, needs and goals - three factors that are interrelated and constitute what Koontz and O'Donnell (1983, pp. 53-55) describe as "a chain reaction".

Leadership skills can be developed through education while personal characteristics are formed over time; the development of an individual's personality is largely determined by the individual's family and social background. Indeed, leaders that exercise leadership behavior are social beings, they are children of society and they emerge from society. While their family environment may differ from their social one, from a psychological perspective, a leader's behavior relates to perceptions, values and mentalities (Saiti, Papa \& Brown 2017). These elements influence the direction of actions and activities that constitute leadership behavior (Deci \& Ryan 2000; Kassotaki, 2011; Saiti, Papa \& Brown 2017; Vallerand, 2000; Vallerand \& Lalande 2011). In addition, individuals, and hence leaders, value the adoption of goals and the mechanisms they use to set goals. This means that realizing the value of leadership is the key to effectiveness. Effective school performance, which is the desired outcome, requires quality school leadership in which the school head/leader has the traits, abilities and initiatives that can steer the school towards high levels of performance.

Based on the above, the purpose of this study is, after a thorough analysis of the relevant literature, to investigate whether strategic/sustainable leadership and effective leadership - key concepts for the educational sector - are synonymous, whether they complement each other, or indeed whether there is an interdependence between these concepts of leadership.

\section{WHAT IS EFFECTIVE LEADERSHIP AND WHO IS AN EFFECTIVE LEADER?}

Leadership is one of the key managerial functions. But what is leadership? Leadership is always a critical issue. Within the context of the analysis and development of management science, leadership is at the forefront of research. Why? Simply because it is the key ingredient for the survival and growth of the organization. How does an organization grow? There is only one way: through the efficient use of human resources. Which managerial function is responsible for the efficient use of an organization's human resources? Leadership. Hence, leadership is responsible for the relationships among the organizational/school members and for motivating them to achieve organizational goals.

Every organization (schools included), operates in a particular environment. In order to ensure a school's survival, it is necessary for it to adjust to the challenges presented by its environment. The organizational/school environment is dynamic: existing standards are changing and new ones are emerging.

Organizational change either involves a change in how organizational goals are achieved or it involves addressing and managing how new organizational goals and environmental challenges are to be achieved (Day \& Sammons, 2013; Everard, Morris \& Wilson, 2004; Parsons \& Beauchamp, 2012; Zheng, Yang \& McLean, 2009 ). So the school needs to adjust to its current environmental standards. Which managerial 
function manages an organization's adjustment? Its leadership. Why? Simply because this managerial function is responsible for the coordination of organizational/school activities and the implementation of programs. Of course, this does not necessarily mean that leadership will definitely have a place in the organizational hierarchy. Leadership is primarily about influencing organizational members to achieve the desired goals. This is because the achievement of organizational goals becomes possible only when the organizational members work together and perform to the best of their abilities.

Based on the above, leadership is about three elements: a) relationships between members b) organizational changes and c) members' motivation. What we observe is that the essence of leadership lies in human relationships and in human beings themselves. Indeed, in order to be able to better manage and achieve the best possible result for an organization, when implementing organizational changes it is necessary to ensure the cooperation and even voluntary cooperation of the relevant stakeholders. Individuals must want to work together. This "want" needs motivation. So leadership is the management of human resource behavior, interpersonal and organizational relationships, and communication (Bush, 2008; Chen, Tsai \& Chen, 2016; Gothard \& Austin, 2013; Hallinger \& Suriyankietkaew, 2018; Harris, 2008, 2010; Mullins, 2010; Zheng, Yang \& McLean, 2009).

For effective leadership, organizational issues and goals need to be approached with sensitivity; a spirit of teamwork and a positive culture need to be established. Why is this necessary? Because only in this way can the organization/school get as close as possible to its desired goals. When we talk about effective leadership, we are implying the effectiveness of the leader.

The concept of "effective leader" consists of two words: "effectiveness" and "leader". Efficiency can be defined as the outcome of certain efforts when all available resources (including human resources) are efficient. A leader is the person who wins the voluntary cooperation of all organizational/school members to achieve the desired goals, such as the result the leader desires. The efficient use of human resources has a positive and direct correlation with voluntary cooperation. They are two interdependent concepts. This is because if the organizational/school members do not cooperate willingly, they will not maximize their performance in order to achieve the desired goals. Therefore, it is not so much a matter of who to choose as an effective leader and how they can be appointed, but is more about the path of leadership. That is, $\underline{\text { how }}$ the leader will achieve both the voluntary cooperation and the efficient use of available resources to achieve the desired result. In order to achieve the goals of a school unit, a school leader must, among other things, exercise effective leadership behavior since, through it, they exert influence on the educators, gain their trust and generally motivate them to attain higher performance (Chen, Tsai \& Chen, 2016; Mendells, 2012).

Human behavior is the result of learning formed by the stimuli that individuals receive from their environment. Therefore, environmental control can affect human behavior, depending on the desired outcome. Hence, if the school environment is positive, then the stimuli the educators will receive will be positive and this will lead to an increased likelihood of positive behavior towards the school.

From a psychological perspective, the law of effect says that when "the consequence of a reaction to an environmental stimulus is pleasant, then the relationship between them is strengthened in the sense that the same reaction is repeated if there is a similar stimulus. If, on the contrary, the result is unpleasant, this relationship is negative in the sense of avoiding the repetition of the same reaction to a similar or very close stimulus ". (Kassotaki, 2011, p. 164)

And who shapes school culture? The school leader. So the question is: what should a school leader do to form a positive culture and win the voluntary cooperation of educators? Much has been written about the practices that an effective leader must follow to achieve maximum school performance. Most leadership studies (Bush,2008; Chen, Tsai \& Chen, 2016; Day \& Sammons, 2013; Day, Gu \& Sammons, 2016; Hitt \& Ireland, 2002; Hollander, 1992; Mendels, 2012; Parsons \& Beauchamp, 2012; Quinn \& Dalton, 2009; Zheng, Yang \& McLean, 2009) focus on these practices. However, after a thorough analysis of the practices of effective leaders, no specific recipe has been found that a leader can follow in order to be effective.

Leadership theories developed on leader effectiveness have focused on four aspects:

a) Personal characteristics / personality traits. This approach focuses on a leader's personality. The personality of the leader is formed at a young age and is influenced by their family and society. Therefore, the personal characteristics of a leader are an integral part of them and are 
not acquired. Also, due to the complexity of human development, there is no convergence of opinion on which personality traits make an effective leader. Even if there was agreement on the characteristics of an effective leader, we still could not be certain because it concerns people and human behavior. The latter is influenced by environmental stimuli and the way we react to events is influenced by our family and our social environment. Therefore, one cannot predict how a given individual will react to environmental stimuli. Based on this, it is very difficult to come up with a list of personal characteristics that will make a leader effective.

b) The behavioral approach, which focuses on leadership style. Based on this approach there are distinct styles that a leader could adopt. But again, leadership behavior is directly related to the behavior of educators and in order to achieve the goal/result, the cooperation of school members is necessary. Furthermore, as has been mentioned above, human behavior is influenced by the environment so we cannot say with certainty which leadership style could lead to greater efficiency.

c) Leadership functions, which focus on the skills that an effective leader must have. While there are no common criteria that converge on the basic skills that an effective leader must acquire, according to the relevant literature, competency groups have been identified that characterize an effective leader, which can be strengthened through training. The main groups are: cooperation, professionalism, empathy, self-control \& understanding, and social skills. However, there is no prescriptive list of skills that a given leader should have in order to be effective.

d) Situational theories, which focus on situations in the work/school environment. It is a combination of leadership functions and leadership behavioral practices. With this approach, individual theories have been developed regarding leadership styles and behavior, depending on the situation. Among these theories is the theory that refers to the maturity of organizational/school members. This theory emphasizes that, for leadership to be effective, it is not enough for the leader to have understanding, personality and leadership skills. It is also necessary for the members of the school to have knowledge, skills and the desire to take responsibility for making decisions. Quite simply, in order for a school to be effective, it is not enough to have an effective leader. It is also essential that its members (educators) have the ability to recognize situations developing and, most importantly, have the maturity to deal with those situations. So effective leadership depends not only on the leader but also on the members.

The leader is responsible for relations between the members, in the sense of creating the appropriate climate, but regarding the maturity of the members, the members of the organization/school are themselves responsible. Therefore, among other things, the effectiveness of a school head depends to a large extent on the quality and maturity of the educators and students (in the sense of school members). Based on the above, effective leadership certainly involves the formation of a supportive school culture, which is the culmination of behavior and leadership style. The question is: how will the school leader develop a positive culture for their school to be effective? Answer: when the expectations of the school leader and the educators converge.

\section{WHAT IS STRATEGIC AND SUSTAINABLE LEADERSHIP?}

\section{Strategic Leadership}

For a school organization, the desired result is a high level of performance in terms of learning outcomes and student achievements, a positive social environment that accepts diversity and of course the sustainability of the school. For this to happen there must be a strategy. Strategic leadership involves first identifying what the organization is and then where it wants to go. Recognition of an organization also involves recognizing the space (environment) in which it operates. School organizations operate in a social environment based on people and not on profit. The primary asset of an educational organization is its human resources and their collectiveness. Of course, staff members are an asset in all organizations, 
regardless of the environment in which they operate. In the case of school organizations, strategic leadership must necessarily have a people-centered approach.

Strategic leadership is primarily an action. The school leader must not only have a vision and set goals, but must know how the strategy will be implemented in order to achieve those goals. Therefore, an important element in strategic leadership is the path of how the strategy will eventually be implemented, in order to achieve the best possible results.

The school leader provides the answer as to how the strategy will be implemented and how the resources will be used in an open school environment that allows for the empowerment of educators and broader outcomes. Indeed, an open work environment is one where the flow of information is flexible, there is interaction between members (Bush, 2008; Day \& Sammons, 2013; Hollander, 1992; Mintzberg, 1987, 1994; Neilson, Martin \& Powers, 2008) and the emphasis is on the behavior of members (educators), not just on the results. We bear in mind that results are a consequence of members' behavior and that the implementation of the strategy is based on the creativity and innovation of those members. As Cunningham \& Harney put it, "Individual creativity is neither mandatory nor compulsory while very little progress has been made in controlling creativity and innovation" (Hatch, 1997, p. 332, cited by Cunningham \& Harney, 2012 , p. 354). Based on the latter, the only way for a school leader to cultivate creativity is to create a positive climate and a culture of collaboration. Therefore, the essential factor in strategic leadership is to establish two-way trust between the school leader and the educators. Through reciprocal trust, educators will be more motivated to consider the school's goals as their own. Thus, educators' commitment to their school can be facilitated which, in turn, instills in them an attitude of determination that will help to ensure that the desired goals are achieved (Bush, 2008; Barney, 1986; Bartlett \& Ghoshal, 2002; Day \& Sammons, 2013; Mintzberg, 1987; Zaleznik, 1977).

The key elements of the strategy are: a) change b) sustainable advantage, and c) difference. All three elements help a school leader to establish a positive and collaborative school culture (Hitt \& Ireland, 2002; Hollander, 1958, 1992; Ireland \& Hitt, 1999; Liedtka, 2000; Waniganayake, Cheeseman, Fenech, Hadley \& Shepherd, 2017).

A sustainable advantage can be gained by managing resources efficiently. But what are the resources within a school that have dynamic capabilities and allow the school leader to implement their strategy in practical terms? Human resources provide the answer. With such support, the school leader can exercise strategic leadership by cultivating the organizational environment necessary to establish a sustainable advantage and thus put their strategy into practice (Ireland \& Hitt, 1999; Liedtka, 2000). Sustainable advantage is the basis for making a school stand out from other schools but, more importantly, it is a strong basis for determining the actions of the strategy and for adapting to environmental changes.

By assessing a school's resources and then making maximum use of them helps the school to maximize its performance. The management and use of the school's (and educators') resources is something that the school leader determines by forming an appropriate school climate. In practice, the success of a strategy lies in transforming human resources' (educators') skills into strategic capabilities that consistently provide superior school value (Cunningham \& Harney, 2012, p. 203) while the champion of a capabilities-based strategy is the school leader (Cunningham \& Harney, 2012, p. 203.). Transforming available school resources into skills is the key to effective school performance.

\section{Sustainable Leadership}

Sustainable leadership is the management of a school's available resources in a manner that brings lasting improvements. The idea of sustainable development, on which the development of sustainable leadership is based, has four dimensions: economic, social, environmental and political. Most of the time, when we talk about sustainable development, there is a tendency to focus only on the environmental dimension. But the natural and social environment are interdependent elements.

Hence, it is important to understand that sustainable leadership does not mean that we should promote only environmental protection and environmental practices, but it calls for a general promotion effort since the social and economic aspects are also of key importance for the development and prosperity of a school. Social development is guided by values, beliefs, attitudes and behaviors and is the basis for sustainability. 
A manager/leader, for example, must understand that the development of a school in a sustainable way presupposes the social development of their school unit as well as the promotion of "real" values such as justice and equality in the school (Conway, 2015; Hargreaves \& Fullan, 2000; Hargreaves \& Fink, 2008; Hollander, 1992; Kempster, Iszatt-White \& Brown, 2019; Quinn \& Dalton, 2009).

The school community, as a subset of society, should recognize the value of their school's existing resources, so that it can develop in a sustainable way and maintain a philosophy of autonomy. Maintaining the sustainable development of a school requires a coordinated effort by, and active involvement of, all those in the school's community. Their active participation is the foundation for sustainable leadership. For this to happen, the school leader must create the right climate to cultivate two-way trust. Therefore, sustainable leadership is based on the human dimension and is "dedicated" to the people, who are the key to improving the school environment. Of course, a successful collaborative culture does not come about automatically but requires effort and, above all, time to cultivate it. It takes willpower and determination.

Sustainable leadership is always looking for ways to improve the quality of professional life (without discrimination) by promoting efficiency and developing the resources available to renew school performance. Sustainable leadership empowers and protects the school. The decision-making process in a school that applies sustainable leadership stems from a civilized coexistence of members as well as the flow of information between school members. Sustainable leadership is a living system operating in the school, where all forces are interdependent and draw strength from each other.

Under sustainable leadership a school is considered to be an ecosystem that is not based on power or hierarchy but protects social justice and attaches special importance to the social unit. Careful stewardship of school resources, in the context of developing sustainable leadership, has a positive effect on resource efficiency and leads to a prudent consumption of energy. Indeed, energy is the key to sustainability and it has to be managed with caution (Conway, 2015; Fullan, 2005; Hollander, 1992).

Efficiency depends largely on maintaining energy balance. The balance is necessary because "overuse of energy is burnout; underuse of energy is atrophy "(Fullan, 2005, p. 37). Indeed, the harmonic use of a school leader's energy is an inspiration to the organization as "the school leader is the energy of the school .... and the school leaders renew the collective energy of those they lead" (Loehr \& Schwartz, 2003, p. 5 cited by Fullan, 2005, p. 35).

A leader's behavior towards the management of energy is heavily dependent on their personal characteristics. Sustainable leadership emphasizes harmony, social coordination and the concept of "community".

Therefore, the school is a community in which efforts and activities are coordinated; communication and cooperation are facilitated on a daily basis to develop the "community" and enhance school performance. As Boukchin (1987, cited by Roseland, 2000, p.92) put it, the school is "an ecological and ethical arena for vibrant political culture and a highly committed educator". Thus, sustainable leadership has a philosophy of creating a safe, open and accessible school environment that satisfies the fundamental principles of equality and justice.

The choice of policies and behaviors must balance philosophy with the ability of school members to respond to information. This can only be done by raising awareness of sustainable school issues. Sustainable thinking is essential: while it may not serve all interests, it strives to strike a balance between serving interests and meeting expectations

Applying sustainable leadership behavior increases a school's ability to absorb any disturbances that result from human behavior, without any adverse effects on school performance. A key component is the human capital of a school, which facilitates social choices and leadership behaviors. This is because the human capital of the school consists of assets and qualities that are (Beatley \& Manning, 1997; Roseland, 2000; White, 2013):

- High value

- Important for the efficient operation of the school

- Irreplaceable for all practical purposes 
Values exist within the school. The question is whether the values will be recognized and, most importantly, appreciated by the school leadership.

The active participation of educators in the school leadership process is directly related to efficient school performance. Sustainable leadership "supports" the sustainable development of the school, as it helps individuals to better understand the relationship between their own expectations and the conditions of the school environment. Indeed, in this way, the improvement of the school environment will be based on new perspectives, while it will be continuous and sustainable (Davies, 2007; Tombaugh, 2005). Thus, school leadership will be leadership for all: "every teacher is a leader and the more that leadership is fostered for everyone, the larger the natural system pool" (Fullan, 2005, p.95). The cultivation, development and maintenance of all school leaders strengthens the cohesion of the school system and its dynamic capabilities. A sustainable leader solves problems and "improves as he does not function properly, within the organization" (Tombaugh, 2005, p. 15) while cultivating social responsibility and creating an atmosphere conducive to trust and the sharing of communication networks (Flora \& Flora, 1993; Swanson, 1992, cited by Roseland, 2000, p. 86). The goal of these communication networks is to increase a school's social productivity, which is the main goal of a school unit (Avery \& Bergsteiner, 2011; Conway, 2015; Day \& Sammons, 2015). Communication networks within the school, among other things, contribute to the implementation of strategies as they promote access to new ideas and expand the creative spectrum, while forming an internal management system for change.

Based on the above, the personality profile of a sustainable school leader could look like the following (Hallinger \& Suriyankietkaew, 2018; Hargreaves \& Fullan, 2000):

- An active and comprehensive thinker

- Concerned with continuity

- Ethical and responsible towards the school, towards "the community"

- Fosters citizenship and collectivity

- Cultivates social networks of communication

- Promotes diversity and the interests of the school

Based on the above, we may say that sustainable leadership is about three crucial elements: a) energy b) change and collaborative networks, and c) action planning. Strategic and Sustainable leadership is about how to implement the strategy and the philosophy of sustainable development. It is also about managing environmentals and establishing collaborative networks within the school (or indeed any organization) so as to respond effectively to environmental changes and to maintain the coherence and dynamic capabilities of the school system. The whole picture of strategic and sustainable leadership is based on the behavior of individuals and on that of the school leader, who is responsible for cultivating the school culture and climate (Avery \& Bergsteiner, 2011; Conway, 2015; Fleet, DeGioia \& Patterson, 2016; Hargreaves \& Goodson, 2006; Hitt \& Ireland, 2002; Lawrence, 2015; Young, 2015).

School leadership is indeed very important but simply setting goals and formulating a strategy have no value without being put into practice; what is required is quality of leadership (Bendell, Sutherland \& Little, 2017; Bush, 2008; Harris \& Spillane, 2008; Hollander, 1992; Lawrence, 2015; Roberston, 2011). Practical implementation necessarily requires a willing collaboration, a spirit of collectivity and team effort. In other words, leadership cannot be effective if there is no commitment and devotion from all in the school. For this to happen, and for leadership to gain value, the position of school leader in the school hierarchy should be downplayed. Instead, everyone in the school should consider that they have a share in the leadership. Only then will the school goals will be considered as a team effort and the sustainable development of the school unit be achieved.

\section{DISCUSSION AND CONCLUSION}

The concept of leadership has the same meaning, whether we talk about effective or strategic/sustainable leadership, because it is based on a philosophy. Moreover, the key question for effective and strategic/sustainable leadership is: how should the desired result be achieved? How will the 
school leader put the various forms of leadership into practice to achieve the desired performance? Also, when we talk about effective school performance, what do we actually mean? A school's performance and its effectiveness is related to outcomes and behaviors. A school outcome is strongly related to the "outputs which is the achievement of the results" (Reeves, et.al., 2002, p. 9). Moreover, the school performance is strongly related to the capabilities and competencies of the human resources. Indeed, human resource competencies largely determine the efficiency of school performance. Utilizing human resources efficiently primarily depends on the school leadership, the conditions of the school environment, and whether the school leader is a good leader in practice (Reeves, et.al., 2002).

All research (Hargreaves, 2009; Harris \& Spillane, 2008; Iszatt-White \& Saunders, 2020; Murray \& McDowall Clark, 2013; Roberston, 2011; Sergiovanni, 1992, 1994; Spillane, 2006; Tian, Rskou \& Collin, 2015; Torrance, 2013; Waniganayake, et.al. 2017; Wright, 2012; Young, 2015; Zaleznik, 1977) on leadership and leadership behavior converges on the view that cooperation and a mature sense of team spirit is certainly the core concern of school leadership. As concerns effective and strategic/sustainable leadership, we may converge on the conclusion that they are essentially identical. They both support the same result, namely, student performance and the establishment of a qualitative and constructive learning environment. All the principles of strategy and sustainable leadership are geared towards achieving the result. Within this framework, strategic and sustainable leadership are the basis for effective leadership. The basic principles on which effective and strategic/sustainable leadership are based are the same, since they both emphasize the importance of cooperation, a constructive culture, a positive psychology, the creation of collaborative social networks, as well as the coexistence of all key elements of school leadership: justice, equality and the efficient use of resources. However, can we consider effective and strategic/sustainable leadership to be synonymous? Well, synonyms are words/concepts that completely identify with one another. In our case, the word interactions and interdependent concepts fully describe the relationship between effective and strategic/sustainable leadership. After all, the acceptance of the strategy by the members of the school and the application of the sustainable principles of leadership make a school leader effective.

The analysis of effective and strategic/sustainable leadership raises the question of how all knowledge and theory will be linked in practice. Based on leadership theories, leadership behavior and the school leader are the result of a harmonious system of various factors that have synergy and balance between them. All factors such as personal characteristics, skills, leadership functions and leadership style have a role in shaping leadership behavior. No factor can be mute.

Through leadership behavior we must nurture and multiply schools' social capital in order to preserve human resources and implement a policy that will enhance the learning, sharing of knowledge and mobilization of educators. Through this process, the promotion of substantial communication networks and the community's vision of the school will be evident.

There are theoretical guidelines available on various forms of leadership that emphasize the development of the school and educators' participation in the decision-making process However, the implementation of a strategic/sustainable leadership, requires more than mere adjustments to existing practices. Intensive efforts for a greater understanding and empathy of the value of resources available within a school and what the school needs are essential elements for the desired school effectiveness (Hollander, 1992; Kempster, Iszatt-White \& Brown, 2019; Quinn \& Dalton, 2009; Wachtel, 1989). This is because sustainable leadership requires a change in thinking, perception and values. Only then may school leaders "yet be able to leave the school a legacy of which they can be proud" (Roseland, 2000, p. 127).

Value-based leadership behavior is one that will provide coherence within the school, and strengthen the confidence and motivation of school members (Bendell, Sutherland \& Little, 2017; Leroy, Anseel, Gardner \& Sels, 2015). Simply exploring values is certainly a beginning but that is not enough. We need vigilance and mobilization in order to find which leadership style or behavior can lead to effectiveness, since "each approach can frame and inform helpful action, while each approach can marginalize important considerations or justify poor action" (Bendell, Sutherland \& Little, 2017, p. 432). What is needed is vigilance on how a leader can help people realize the importance of "being together, living together" 
In conclusion, leadership and leadership behavior is a philosophy of attitude, which we can summarize using the words of Nobel Prize-winning philosopher Albert Camus: "the impact of leadership behavior on school performance and especially the behavior of organizational members, is the sum of the leader's choices; The chair of power is not a moral attitude for a leader; The leader must walk always with the teachers, to become their companion; The need for the leader to always be right is a seal of a vulgar spirit; Collectivity and creativity are like living twice; Everything that happens in the organization-school, the real leader wants to be there."

\section{ACKNOWLEDGEMENTS}

I would like to thank the University of West Attica for paying my subscription to the Journal.

\section{REFERENCES}

Avery, G.C., \& Bergsteiner, H. (2011). Sustainable leadership practices for enhancing business resilience and performance. Strategy \& Leadership, 39(3), 5-15.

Barney, J.B. (1986). Organizational culture: Can it be a source of competitive advantage? The Academy of Management Review, 11(3), 656-665.

Bartlett, C., \& Ghoshal, S. (2002). Managing across borders: The transnational solution (Second edition). Boston MA: Harvard Business School Press.

Beatley, T., \& Manning, K. (1997). The ecology of place: Planning for environment, economy and community. Washington: Island Press.

Bendell, J., Sutherland, N., \& Little, R. (2017). Beyond unsustainable leadership: Critical social theory for sustainable leadership. Sustainability Accounting Management and Policy Journal, 8(4), 418-444.

Bookchin, M. (1987). The Rise of Urbanization and the Decline of Citizenship. Sierra Club, San Francisco, CA.

Bush, T. (2008). From management to leadership: Semantic or meaningful change? Educational Management Administration \& Leadership, 36(2), 271-288.

Chen, C.Y., Tsai, S. ., Chen, H.W., \& Wu, H.T. (2016). The relationship between the principal's positive leadership and school effectiveness - take school organizational culture as the mediator.

European Journal of Psychological Research, 3(2). Retrieved from https://www.idpublications.org/wp-content/uploads/2016/07/Full-Paper-THE-

Conway, J.M. (2015). Sustainable leadership for sustainable school outcomes: Focusing on the capacity building of school leadership. Leading and Managing, 21(2), 29-45. Retrieved from https://www.researchgate.net/publication/292988747

Cunningham, J., \& Harney, B. (2012). Strategy \& Strategists. U.K.: Oxford University Press.

Davies, B. (2007). Developing sustainable leadership. Management in Education, 21(3), 4-9.

Day, C., \& Sammons, P. (2013). Successful leadership: A review of the international literature. $C f B T$ Education Trust. Retrieved from http://eric.ed.gov/?id=ED546806

Day, C., Gu, Q., \& Sammons, P. (2016). The impact of leadership on student outcomes: How successful school leaders use transformational and instructional strategies to make a difference. Educational Administration Quarterly, 52(2), 221-258. doi: https://doi.org/10.1177\%2F0013161X15616863

Deci, E.L., \& Ryan, R.M. (2000). The "What" and "Why" of goal pursuits: Human needs and the selfdetermination of behaviour. Psychological Inquiry, 11(4), 227-268.

Everard, K.B., Morris, G., \& Wilson, I. (2004). Effective school management (Fourth edition). London: Paul Chapman Publishing.

Fleet, A., DeGioia, K., \& Patterson, C. (2016). Engaging with educational change: Voices of practitioner inquiry. London: Bloomsbury Publishing

Flora, C.B., \& Flora, J.L. (1993). Entrepreneurial social infrastructure: a necessary ingredient. Annals of the American Academy of Political and Social Science, 529, 48-58.

Fullan, M. (2005). Leadership \& Sustainability. System thinkers in action. U.S.A.: Corwin Press. 
Gothard, S., \& Austin, M.J. (2013). Leadership succession planning: Implications for nonprofit human service organizations. Administration in Social Work, 37(3), 272-285.

Hallinger, P., \& Suriyankietkaew, S. (2018). Science mapping of the knowledge base on sustainable leadership, 1990-2018. Sustainability, 10, 4846. doi:10.3390/su10124846

Hargreaves, A. (2009). A decade of educational change and a defining moment of opportunity - An introduction. Journal of Educational Change, 10(2-3), 80-100.

Hargreaves, A., \& Fink, D. (2008). Distributed leadership: democracy or delivery? Journal of Educational Administration, 46(2), 229-240.

Hargreaves, A., \& Fullan, M. (2000). Mentoring in the New Millennium. Theory Into Practice, 39(1), 5056

Hargreaves, A., \& Goodson, I. (2006). Educational change over time? The sustainability and nonsustainability of three decades of secondary school change and continuity. Educational Administration Quarterly, 42(1), 3-41.

Harris, A. (2005). Leading from the Chalk-face: An overview of school leadership. Leadership, 1(1), 7387.

Harris, A. (2008). Distributed School Leadership: Developing tomorrow's leaders (London, UK: Routledge).

Harris, A. (2010). Distributed leadership: Evidence and implications. In T. Bush, L. Bell, \& D. Middlewood (Eds.), The principles of educational leadership \& management (Second Edition, pp. 55-69). London: Sage Publication.

Harris, A., \& Spillane, J. (2008). Distributed leadership through the looking glass. Management in Education, 22(1), 31-34.

Hatch, M.J. (1997). Organization theory: Modern Symbolic and Postmodern Perspectives. Oxford: Oxford University Press.

Hitt, M.A., \& Ireland, R.D. (2002). The essence of strategic leadership: Managing human and social capital. Journal of Leadership and Organizational Studies, 9(1), 3-14.

Hollander, E.P. (1958). Conformity, status and idiosyncracy credit. Psychological Review, 65, 117-127.

Hollander, E.P. (1992). Leadership, followership, self and others. The Leadership Quarterly, 3(1), 43-54.

Ireland, R.D., \& Hitt, M.A. (1999). Achieving and maintaining strategic competitiveness in the $21 \mathrm{st}$ century: The role of strategic leadership. Academy of Management Executive, 13(1), 43-57.

Iszatt-White, M., \& Saunders, C. (2020). Leadership (Third Edition). U.S.A.: Oxford University Press.

Judge, T.A., Bono, J.E, Ilies, R., \& Gerhardt, M.W. (2002). Personality and leadership: A qualitative review. Journal of Applied Psychology, 87(4), 765-780.

Kassotaki-Maridaki, A. (2011). Pedagogical Psychology. Athens, Greece: Diadrasi Publications (in Greek).

Kempster, S., Iszatt-White, M., \& Brown, M. (2019). Authenticity in leadership: Reframing relational transparency through the lens of emotional labour. Leadership, 15(3), 319-338.

Koontz H., \& O'Donnell, C. (1983). Organisation and Administration, (Translation into Greek Language Vardakos, C.) Athens, Greece: Papazisi Publications, (in Greek).

Lawrence, P. (2015). Leading change-insights into how leaders actually approach the challenge of complexity. Journal of Change Management, 15(3), 231-252.

Leroy, H., Anseel, F., Gardner, W.L., \& Sels, L. (2015). Authentic leadership, authentic followership, basic need satisfaction, and work role performance a cross-level study. Journal of Management, 4l(6), 1677-1697.

Liedtka, J. (2000). In Defense of Strategy as Design. California Management Review, 42(3), 8-30.

Loehr, J., \& Schwartz, T. (2003). The power of full engagement. New York: Free Press.

Mendels, P. (2012). The effective principal. Journal of Staff Development, 33(1), 54-58.

Mintzberg, H. (1987). The Strategy Concept II: Another Look of Why Organisations Need Strategies. California Management Review, 30(1),25-32.

Mintzberg, H. (1994). The rise and fall of strategic planning. New York: Free Press.

Mullins, L.J. (2010). Management and Organisational Behavior (Ninth Edition). London: Prentice Hall.

Murray, J., \& McDowall Clark, R. (2013). Reframing leadership as a participative pedagogy: The working theories of early years professionals. Early Years, 33(3), 289-301. 
Nielson, G., Martin, K., \& Powers, S. (2008). The secrets to successful strategy execution. Harvard Business Review, 86(6), 60-70.

Parsons, J., \& Beauchamp, L. (2012). Leadership in Effective Elementary Schools: A Synthesis of Five Case Studies. Online Submission. US-China Education Review B, (8), 697-711. Retrieved from https://files.eric.ed.gov/fulltext/ED536409.pdf

Quinn, L., \& Dalton, M. (2009). Leading for sustainability: Implementing the tasks of leadership. Corporate Governance: International Journal of Business in Society, 9(1), 21-38.

Reeves, J., Forde, C., O’Brien, J., Smith, P., \& Tomlinson, H. (2002). Performance management in education: improving practice. London: Sage Publications.

Robertson, J. (2011). Partnership in leadership and learning. In J. Robertson \& H. Timperley (Eds.), Leadership and Learning (pp. 213-226). London: Sage Publishing.

Roseland, M. (2000). Sustainable community development: Integrating environmental, economic and social objectives. Progress in Planning, 54, 73-132.

Saiti, A., Papa, R., \& Brown, R. (2017) Post-Graduate-Students Factors on Program Choice and Expectation. Journal of Applied Research in Higher Education, 9(3), 407-423

Sergiovanni, T. (1992). Moral leadership: Getting to the heart of school leadership. San Francisco: Jossey Bass.

Sergiovanni, T. (1994). Organizations or communities? Changing the metaphor changes the theory. Educational Administration Quarterly, 30(2), 214-226.

Spillane, J.P. (2006). Distributed Leadership. San Francisco: Jossey Bass.

Swanson, L. (1992). Rural social infrastructure. In J.N. Reid (Ed.), Foundations of Rural Development Policy. Westview Press, Boulder, CO.

Tian, M., Riskou, M., \& Collin, K. (2016). A meta analysis of distributed leadership from 2002 to 2013 : Theory development, empirical evidence and future research focus. Educational Management Administration and Leadership, 44(1),146-164.

Tombaugh, J.R. (2005). Positive leadership yields performance and profitability: Effective organizations develop their strengths. Development and Learning in Organizations: An International Journal, 19(3), 15-17.

Torrance, D. (2013). Distributed leadership: Challenging five generally held assumptions. School Leadership \& Management, 33(4), 354-372

Vallerand, R.J., \& Lalande, D.R. (2011). The MPIC Model: The perspective of the hierarchical model of intrinsic and extrinsic motivation. Psychological Inquiry, 22(1), 45-51.

Vallerand, R.J. (2000). Deci and Ryan's self-determination theory: A view from the hierarchical model of intrinsic and extrinsic motivation. Psychological Inquiry, 11(4), 312-318.

Wachtel, P. (1989). The Poverty of Affluence: A Psychological Portrait of the American Way of Life. Gabriola Island, BC: New Society Publishers.

Waniganayake, M., Cheeseman, S., Fenech, M., Hadley, F., \& Shepherd, W. (2017). Leadership: Contexts and complexities in early childhood education (Second Edition). Australia: Oxford University Press.

White, C.S. (2013). Sustainability in the Arenas of power: An exploration of public policy. In J.E. Davis \& R.A. Diem (Eds.), Sustainability, growth and globalization: A social science perspective (pp. 35-47). U.S.A.: IAP - Information Age Publishing Inc.

Wright, D. (2012). A Qualitative Look at Leadership Succession in Human Service Organizations. International Leadership Journal, 4(3),18-28.

Young, H. (2017). Knowledge, experts and accountability in school governing bodies. Educational Management Administration and Leadership, 45(1), 40-56.

Zaleznik, A. (1977). Managers and Leaders: Are they different? Harvard Business Review, Classic, pdf file (16 pages). Retrieved from https://hbr.org/2004/01/managers-and-leaders-are-they-different

Zheng, W., Yang, B., \& McLean, G.N. (2013). Linking organizational culture, structure, strategy, and organizational effectiveness: Mediating role of knowledge management. Journal of Business Research, 63, $763-771$.

136 Journal of Leadership Accountability and Ethics Vol. 18(1) 2021 